\title{
Promises of silent salesman to the FMCG industry: an investigation using linear discriminant analysis approach
}

\author{
Dr. Suraj Kushe SHEKHAR \\ VIT University, India \\ Dr. P.T. RAVEENDRAN \\ Kannur University, India
}

\begin{abstract}
Packaging which is often called as the 'silent salesman' is an important component of marketing. Today the importance of packaging has risen to such an extent that product packaging is rightly called as the fifth ' $P$ ' of marketing mix. FMCG are products which are utilized by large number of people. The present study examined the discriminating power of five selected FMCG packaging variables namely 'picture', 'colour', 'size', 'shape' and 'material' amidst those who purchased FMCG based on these packaging variables and for those who purchased FMCG not based on these packaging variables. Descriptive research was carried out in the study. Respondents (students) were asked to rate four packaging variable on a five point Likert's scale. Discriminant analysis showed that only two variables namely 'Colour' (.706) and 'Shape' (-.527) were good predictors. Variables 'Picture', 'size' and 'material' were considered as poor predictors as far as the student communities were considered. The cross validated classification showed that out of the 240 samples drawn, $91.8 \%$ of the cases were correctly classified.
\end{abstract}

Keywords: Consumers, Discriminant analysis, FMCG, Packaging, Purchase

Please cite the article as follows: Shekhar, S.K. and Raveendran, P.T. (2015), "Promises of silent salesman to the FMCG industry: an investigation using linear discriminant analysis approach", Management \& Marketing. Challenges for the Knowledge Society, Vol. 10, No. 4, pp. 304-315, DOI: 10.1515/mmcks-2015-0020.

\section{Introduction}

Product package is regarded as a major component of marketing. In earlier days packaging was regarded as a sheer protective tool but today, it is considered as a major element of the marketing process. Today product package is often positioned as the fifth ' $\mathrm{P}$ ' of the marketing mix. Pilditch (1961) was the first to propose packs as the 'silent salesman'. Lewis (1991) extended Pilditch's (1961) views, describing good packaging as far more than a salesman but a flag of recognition and a symbol of values. Vazquez, Bruce and Studd (2003) mentioned that product package must come alive at the point of purchase, in order to symbolize as the 'salesman'. Richardson et al. (1994) later mentioned packages being associated to the product but with extrinsic properties. Underwood (2003) suggested product packages constituting intrinsic or extrinsic attributes based on certain features they possessed.

Correspondence: Suraj Kushe Shekhar surajkushe@ gmail.com 
Fast-moving consumer goods (FMCG) or consumer packaged goods (CPG) are products that are sold quickly and at relatively low cost. Examples include non-durable goods such as soft drinks, toiletries, over-the-counter drugs, toys, processed foods and many other consumables. In contrast, durable goods or major appliances such as kitchen appliances are generally replaced over a period of several years. The term FMCG was coined by Neil H. Borden in 'The Concept of the Marketing Mix' in 1965.

Based on the results from previous researches, this paper makes an attempt to identify the level of influence of five major visual FMCG packaging variables ('picture', 'colour', 'size', 'shape' and 'material') on young consumers' purchase behaviour. The paper uses a Linear Discriminant Analysis (LDA) approach to identify which variable/s discriminated between those who purchased FMCG based on packaging variable/s and those who purchased FMCG not based on packaging variable/s.

\section{Literature review \\ Colour on product packages}

Hollywood et al. (2013) highlighted that the majority of participants found milk packaging to be functional; however, beyond this use, vast improvement could be made in terms of the aesthetics surrounding packaging design particularly the colour of the package. Silayoi and Speece (2007) in their article mentioned that visual components of package influence purchase decisions more than informational elements. Madden et al. (2000) stated the marketer's must consider color as integral part of their marketing strategies. They further opined that taking the colors of a particular logo, package, or product design from one market to another must be done through a thorough understanding of how colors and the color combinations are perceived in each location.

Colour is considered the most important tool for emotional expression of a package (Hine, 1995) as it reflected an image for the product (Sauvage, 1996). Underwood (2003) opined that consumers associated meaning to the package colours in three different ways: the 'physiological', the 'cultural', and the 'associational'. The first one was described as universal and involuntary (e.g. the colour red speeding the pulse). The second one, cultural, occurred over long periods of time in different societies (e.g. the colour black relates to elegance in Europe). The third one, associational, was developed through marketing efforts (e.g. the colour pink relates to the product with low calories). In addition, colour was considered as a tool for brand identification and visual distinction (Underwood, 2003). Colour was also considered as an important factor for legibility of the texts and comprehension of the images placed on the package. Meyers-Levy and Peracchio (1995) opined that color, which is assumed to be more vivid than black and white, attracted attention and could provide information. It was observed that a product must stand out from the clutter of the competing brands in order to succeed and color had a great role to catch the needed attention (Fitzgerald and Russo, 2001; Meyers-Levy and Peracchio, 1995).

However it was also perceived that color attracted attention to irrelevant data in a situation when colorful graphics used consumers' resources in examining the verbal component of the package leading to an incorrect conclusion on the product (Fitzgerald and Russo, 2001). Particularly in a grocery shop, consumers relied on cues that they could quickly assess (Richardson et al., 1994) and therefore if the product's color evoked associations that conflicted with actual product features, the risk of choosing a bad product 
was possible. The notion of color associations was found to be quite complex. On one hand, consumers seemed to have personal and cultural preferences for some colors over others (Grossman and Wisenblit, 1999). On the other hand, entire product classes seemed to have sets of 'acceptable' colors (Schoormans and Robben, 1997) and these sets seemed to be independent of personal color preferences.

According to Grossman and Wisenblit (1999), favorite color did not efficiently explain consumer color choices for products. Consumers developed a wide range of color associations for various product contexts, which made the task of understanding color responses more complicated. They further added that rather than examining general color preferences among consumers, it was preferable to learn consumers' color associations as a basis for understanding the emotional aspects of color. Color associations seemed to be influenced by numerous aspects. Ampuero and Vila (2006) found some color associations which they stated could cross category boundaries. The authors found that packaging in cold and dark colors were usually associated with high-prices and refined aesthetics. In contrast, accessible products that were directed to price sensitive consumers required light, mainly white, colored packaging. Safe and guaranteed products were associated with red packaging. Whether these results demonstrate an innate meaning of color to consumers or only a set of color associations learned from existing product categories, however, remains unclear till date.

\section{Size and shape on product packages}

Clement et al. (2013) found that during shopping, physical design features such as shape and contrast dominate the initial phase of searching. Raghubir and Greenleaf (2006) mentioned that consumers used these things as simplifying visual heuristics to make volume judgments. They further explained that even if consumers frequently purchased the same package and had experience using them, they perceived more elongated packages to be better. Thus, elongating the shape, within acceptable bounds, resulted in consumers thinking of the package as a better value for money and resulted in larger sales. They further added that disconfirmation of package size after consumption may not lead consumers to revise their volume judgment sufficiently in the long term, especially if the discrepancy was not that large.

As per Silayoi and Speece (2004), package size, shape, and elongation affected consumer assessment and decisions, much like graphical elements. They found that size and shape were much related to usability. They further argued that when consumers thought of product pictures and graphics being considered as a means of communication, argument about size and shape focused more on packages being convenient to use and carry. Participants opined that packaging size and shape helped them judge product volume and value for money (Silayoi and Speece, 2007). Without their household brands, bigger packages of very low involvement goods such as commodity food products tended to be chosen (Silayoi and Speece, 2004).According to Prendergast and Pitt (1996), different types of packaging sizes appealed to consumers with different involvement levels. They argued that for some low involvement food products, such as generics, low price was made possible through cost savings created by reduced packaging and promotional expenditures. Since generics were usually packaged in large sizes, this directly catered to the needs of consumers from larger households, who were more inclined in looking for 
good deals. They found the low price of the generics, in larger packaging, as an attractive offer with superb value for money. It was also implied that when product quality was hard to be determined, the effect of packaging size was much stronger.

\section{Pictures on product packages}

Clement et al. (2013) indicated that consumers have fragmented visual attention during grocery shopping, and that their visual attention is simultaneously influenced and disrupted by the shelf display. According to Rettie and Brewer (2000), pictorial elements on packages largely influenced purchase decision. Further, the placement of these elements also marked significant influence on purchase decisions. Research indicated that brain laterality showed an asymmetry in the perception of the elements in package designs. The recall of packaging elements was likely to be inclined by their lateral position on the package, as well as by other usually distinguished factors, such as font style, size, and color. Recall was found to be enhanced for verbal stimuli when the copy (picture) was on the right-hand side of the product package, and superior for non-verbal stimuli when it is on the left-hand side of the package. It was thus concluded that in order to maximize consumers' recall, pictorial elements on the package had to be placed on the left-hand side of the package.

MacInnis and Price (1987) stated that a consumer screening a product picture on a package was more inclined to spontaneously imagine aspects of how a product looked, tasted, felt, smelled, or sounded like than they would with a package without a picture on it. According to them, the imaging of the individual brand then leaded to fewer brands being evaluated, enhancing the brand's likelihood of purchase. Underwood et al. (2001), on the other hand, stated that the positive influence of package picture was primarily to increase attention to a brand, rather than augment the likelihood of the brand to be chosen. According to them, pictures were considered to be exceedingly vivid stimuli and depicting visual imagery on a package enhanced the product's accessibility to consumers, which did not find to be synonymous to brand choice.

Alternatively, Fitzgerald and Russo (2001) opined a picture's capacity to serve as a framework for interpreting a package's informational components, since pictures, according to them, were likely to be processed prior to other components of a package. Therefore, on one side, a picture could strengthen the informational, for example verbal, stimuli. On the other side, if a package was not carefully designed, the two components could contradict and in that case, Fitzgerald and Russo's (2001) statement implied that the intended informational stimuli would be held back. According to Underwood et al. (2001) the picture could also serve as a source of information to a consumer. Pictorial content conveyed a solid information that directed to be more powerful in the decision making process than more abstract verbal information. A picture could actually show how the product looked like or how it could be served, while verbal information could only describe it (Underwood et al., 2001). Moreover, in categories where product knowledge was lower, the product picture proved to be highly diagnostic (Underwood et al., 2001), as it revealed the unknown product in a way that inspired consumers' mind. Also if little variance existed in price and perceived quality among brands, a product picture was exceedingly important (Underwood et al., 2001). 


\section{MMCKS Material on product packages}

Ashby and Johnson (2013) described packaging material as an important element of package design. Package designers utilize a wide array of materials, including paper, cardboard, plastics, glass, wood, metals, and combinations of all (Fitzgerald and Tsosie, 2004). The nature of contents, functional needs, and the product picture were all considered important while determining the right type of material (Sonsino, 1990; Sauvage, 1996). As the shape of a package generated an idea about the brand and the product, the selected material for a package also affected consumer mindset. For example, glass was considered as a high-quality image on consumers' minds, at the same time metal packages had an old fashioned image or plastics were considered as low-quality image for particularly older consumers (Sauvage, 1996). If the shape of a package affected the design of the area used for the label, the material of the label affected the print colours. Despite the differentiation of package design components during the design process, these elements were to be carefully combined to constitute the overall design quality (Sonsino, 1990).

The literature discussed above gives an exhaustive idea the extend of importance of visual packaging variables namely 'picture', 'colour', 'size', 'shape' and 'material'. However, the literature only describes the significance of these variables w. r. t. to product packaging in general. So far little empirical evidence exists regarding the impact of these variables on purchase decisions of FMCG based on packages. Studies haven't been conducted to find out if these variables clearly discriminated between those who purchased FMCG based on packages and those who purchased FMCG not based on packages. The present study would bridge the gap in understanding such a scenario.

\section{Research methodology}

Descriptive type of research (Malhotra, 2004) was designed for the study. The study identified the opinion of young consumers which mainly comprised post graduate students. Questionnaire was designed on a five point Likert's scale. Respondents (students) were asked to rate the level of influence of four packaging variables ('picture', 'colour', 'size', 'shape' and 'material') on this scale. Respondents fell in age group between 20-25 years. Convenient sampling was used as the sampling technique and a total of 240 responses were collected. Primary data was used in the study and data collection was undertaken in the form of a filed survey. Data collection was carried out in various colleges in Kannur district, Kerala State, India. Majority (84\%) of the respondents fell in the age group of 2224 years. $52 \%$ of the respondents were females. $46 \%$ of the respondents were from cities followed by towns (32\%) and villages (22\%).92\% of the respondents were unmarried (Table 1).

Table 1. Frequency statistics

\begin{tabular}{|c|c|c|}
\hline Demographics & Details & Percentage \\
\hline Age group & $22-24$ & $82 \%$ \\
\hline Sex & Male & $48 \%$ \\
\hline Place of residence & City & $46 \%$ \\
\hline Marital status & Unmarried & $92 \%$ \\
\hline
\end{tabular}

Source: Authors' own research result. 
Discriminant analysis is a statistical analysis to predict a categorical dependent variable (called a grouping variable) by one or more continuous or binary independent variables (called predictor variables). Discriminant analysis is used when groups are known a priori (unlike in cluster analysis). Each case has a score on one or more quantitative predictor measures, and a score on a group measure. In simple terms, discriminant function analysis is classification - the act of distributing things into groups, classes or categories of the same type (Johnson and Wichern, 1992).

The discriminant function $\mathrm{D}$ which predicts which group the case belongs can be written as

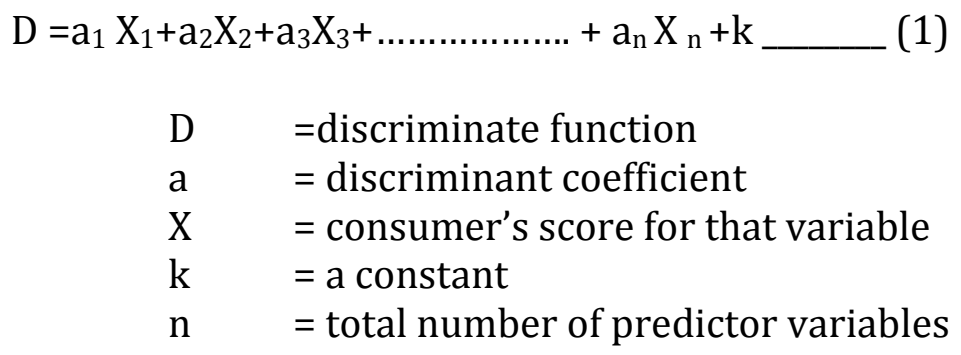

A discriminant analysis was carried out on five variables namely 'picture', 'colour', 'size', 'shape' and 'material' (predictor variables).The categorical dependent variable were consumers who bought FMCG based on packaging variable/s and those who bought FMCG not based on packaging variable/s. Thus the hypothesis of the entire study was designated as:

H0: Does visual elements ('picture', 'colour', 'size', 'shape' and 'material') allow one to discriminate between those who buy FMCG based on package and those who purchase FMCG not based on package?

Data obtained through the survey were subjected to discriminant analysis using SPSS software package (Version 16) .Results was interpreted at 95 percent confidence interval.

\section{Results and discussions}

The mean differences (Table 2) indicated the variables to be good discriminators (between the two groups) as the separation between them were found to be large. Results (Table 3), further supported the existence of strong significant differences (for all the independent variables with 'colour' and 'size' indicating very high values for F's) between means of those who purchased FMCG based on package and those who purchased FMCG not based on package (Table 4).

Table 2. Statistics

\begin{tabular}{|c|c|l|c|c|c|}
\hline Response & Variables & Mean & Std. Deviation & \multicolumn{2}{|c|}{ Valid N (listwise) } \\
\hline & & & & Unweighted & Weighted \\
\hline No & Picture & 38.4665 & 9.23647 & 105 & 105.000 \\
\hline & Size & 46.6148 & 11.16826 & 105 & 105.000 \\
\hline & Colour & 19.6848 & 5.23565 & 105 & 105.000 \\
\hline
\end{tabular}

Vol.10, No. 4, Winter, pp. 304-315, ISSN 1842-0206 | Management \& Marketing. Challenges for the Knowledge Society 


\begin{tabular}{|c|c|c|c|c|c|c|}
\cline { 2 - 6 } MMCKS & Shape & 4.8482 & 5.39643 & 105 & 105.000 \\
\cline { 2 - 6 } & & Material & 22.6770 & 2.56036 & 105 & 105.000 \\
\cline { 2 - 7 } & & Picture & 36.1934 & 8.52325 & 135 & 135.000 \\
\cline { 2 - 7 } & Yes & Size & 28.2818 & 6.54159 & 135 & 135.000 \\
\cline { 2 - 7 } & & Colour & 28.5028 & 7.25153 & 135 & 135.000 \\
\hline & Shape & 8.3481 & 7.53107 & 135 & 135.000 \\
\cline { 2 - 7 } & & Material & 20.6409 & 3.15670 & 135 & 135.000 \\
\hline & Picture & 37.7032 & 9.02823 & 240 & 240.000 \\
\hline & Size & 39.0388 & 13.12921 & 240 & 240.000 \\
\hline & Colour & 23.3288 & 7.52428 & 240 & 240.000 \\
\hline & Shape & 6.2945 & 6.58773 & 240 & 240.000 \\
\hline & Material & 21.8356 & 2.99204 & 240 & 240.000 \\
\hline
\end{tabular}

Source: Authors' own research result.

Table 3. Equality tests (group means)

\begin{tabular}{|c|c|c|c|}
\hline & $\begin{array}{c}\text { Wilks' } \\
\text { Lambda }\end{array}$ & F & Sig. \\
\hline Picture & .980 & 8.781 & .003 \\
\hline Size & .526 & 392.672 & .000 \\
\hline Colour & .666 & 218.439 & .000 \\
\hline Shape & .931 & 32.109 & .000 \\
\hline Material & .887 & 55.295 & .000 \\
\hline
\end{tabular}

Source: Authors' own research result.

Table 4. Within groups matrices (pooled)

\begin{tabular}{|l|c|c|c|c|c|c|}
\hline & & Picture & Size & Colour & Shape & Material \\
\hline \multirow{3}{*}{ Correlation } & Picture & 1.000 & -.118 & .060 & .042 & .061 \\
\cline { 2 - 7 } & Size & -.118 & 1.000 & .042 & -.143 & -.044 \\
\cline { 2 - 7 } & Colour & .060 & .042 & 1.000 & .118 & .137 \\
\cline { 2 - 7 } & Shape & .042 & -.143 & .118 & 1.000 & .116 \\
\cline { 2 - 7 } & Material & .061 & -.044 & .137 & .116 & 1.000 \\
\hline
\end{tabular}

Source: Authors' own research result.

Although the log determinants (Table 5) appeared to be similar across the two groups, the Box's M (Table 6) showed that the assumption of equality of covariance matrices was not met. However as the sample size was 240 which are considered to be large for discriminant analysis, this problem was not regarded as that serious.

Table 5. Log determinants

\begin{tabular}{|c|c|c|}
\hline Response & Rank & $\begin{array}{c}\text { Log } \\
\text { Determinant }\end{array}$ \\
\hline No & 5 & 17.631 \\
\hline Yes & 5 & 18.058 \\
\hline Pooled within-groups & 5 & 18.212 \\
\hline
\end{tabular}

Source: Authors' own research result. 
Table 6. Test results (box's $m$ )

\begin{tabular}{|c|c|c|}
\hline \multicolumn{2}{|c|}{ Box's M } & 176.474 \\
\hline \multirow{3}{*}{ F } & Approx. & 11,615 \\
\cline { 2 - 3 } & df1 & 15 \\
\cline { 2 - 3 } & df2 & 600825.3 \\
\cline { 2 - 3 } & Sig. & .000 \\
\hline
\end{tabular}

The canonical correlation (Table 7) analysis which is used to identify and measure the associations among two sets of variables indicated the relation between the independent variables and the discriminant function explaining 64.32\% (canonical correlation $=.802$ ) of the variation in the grouping variable, i.e. whether a customer purchased a FMCG based on packaging attributes and those who purchased a FMCG not based on packaging attributes. Wilks' Lambda test (Table 8) which narrates which variable contribute significantly to the discriminant function indicated that $35.6 \%$ of the cases were not explained.

Table 7. Canonical correlation

\begin{tabular}{|c|c|c|c|c|}
\hline Function & Eigenvalue & $\%$ of Variance & Cumulative \% & $\begin{array}{l}\text { Canonical } \\
\text { Correlation }\end{array}$ \\
\hline 1 & 1.806 & 100.0 & 100.0 & .802 \\
\hline
\end{tabular}

Source: Authors' own research result.

Table 8. Wilks' lambda

\begin{tabular}{|l|r|r|r|c|}
\hline Function(s) Test & $\begin{array}{c}\text { Wilks' } \\
\text { Lambda }\end{array}$ & Chi-square & df & Sig. \\
\hline 1 & \multicolumn{2}{|r|}{.356} & 447.227 & \multicolumn{3}{r|}{5} & .000 \\
\hline
\end{tabular}

Further the structure matrix (Table 9) revealed that 'Colour' (high score) and 'Shape' (low score) clearly discriminated between those who purchased FMCG based on packaging attributes and those who purchased a FMCG not based on packaging attributes. 'Picture' and 'Material' were positively loaded which indicated these variables being associated with purchase behavior. Size was negatively loaded which indicated that this variable was not associated with purchase behavior. Canonical discriminant analysis which derives linear combinations of the interval variables and also summarizes between-class variation indicated that (Table 10) the discriminant function was a linear combination of various coefficients and can be represented in the form of equation 1. Further, the unstandardized canonical discriminant functions evaluated at group means (Table 11) indicated that group centroids closer to 1.125 were purchases not based on packages and group centroids closer to -1.598 were purchases based on packages.

The results of the classification matrix (Table 12) showed that $91.8 \%$ of respondents were classified correctly into 'purchases not based on packages' or 'purchases 
MMCKS based on packages' groups. 'Purchases not based on packages' were classified with slightly better accuracy (92.6\%) than 'purchases based on packages' (90.6\%).

\section{2}

Table 9. Structure matrix

\begin{tabular}{|c|c|}
\hline \multirow{2}{*}{ Variables } & Function \\
\cline { 2 - 2 } & 1 \\
\hline Colour & .706 \\
\hline Shape & -.527 \\
\hline Picture & .265 \\
\hline Size & -.202 \\
\hline Material & .106 \\
\hline
\end{tabular}

Source: Authors' own research result.

Table 10. Canonical discriminant function unstandardized coefficients

\begin{tabular}{|c|c|}
\hline \multirow{2}{*}{ Variable } & Function \\
\cline { 2 - 2 } & 1 \\
\hline Colour & .024 \\
\hline Shape & .080 \\
\hline Picture & -.100 \\
\hline Size & -.012 \\
\hline Material & .134 \\
\hline (Constant) & -4.543 \\
\hline
\end{tabular}

Source: Authors' own research result.

From Table 10, the discriminant score for equation (1) is rewritten as

$$
\mathrm{D}=(.24 \times \text { Colour })+(.080 \times \text { Shape })+(-.100 \times \text { Picture })+(-.012 \times \text { Size })+(.134 \times \text { Material })-
$$

Table 11. Group centroids

\begin{tabular}{|c|c|}
\hline Response & Function \\
\hline & 1 \\
\hline No & 1.125 \\
\hline Yes & -1.598 \\
\hline
\end{tabular}

Source: Authors' own research result.

Table 12. Classification

\begin{tabular}{|c|c|c|c|c|c|}
\hline \multirow{2}{*}{} & & \multicolumn{2}{|c|}{$\begin{array}{c}\text { Predicted Group } \\
\text { Membership }\end{array}$} & \multirow{2}{*}{} \\
\cline { 3 - 5 } & & Response & No & Yes & Total \\
\hline \multirow{3}{*}{ Original } & \multirow{2}{*}{ Count } & No & 97.3 & 7.7 & 105 \\
\cline { 3 - 6 } & & Yes & 12.6 & 122.4 & 135 \\
\cline { 3 - 6 } & \multirow{2}{*}{$\%$} & No & 92.6 & 7.4 & 100.0 \\
\cline { 3 - 5 } & & Yes & 9.4 & 90.6 & 100.0 \\
\hline
\end{tabular}

Vol. 10, No. 4, Winter, pp. 304-315, ISSN 1842-0206 | Management \& Marketing. Challenges for the Knowledge Society 


\begin{tabular}{|c|c|c|c|c|c|}
\hline & & & & & \\
\hline \multirow{3}{*}{$\begin{array}{c}\text { Cross- } \\
\text { validated }\end{array}$} & Count & No & 97.3 & 7.7 & 105 \\
\cline { 2 - 6 } & & Yes & 12.6 & 122.4 & 135 \\
\cline { 2 - 6 } & \multirow{2}{*}{$\%$} & No & 92.6 & 7.4 & 100.0 \\
\cline { 2 - 6 } & & Yes & 9.4 & 90.6 & 100.0 \\
\hline
\end{tabular}

\section{Conclusions, managerial implications and limitations}

A discriminant analysis was conducted to access whether consumers purchased FMCG based on package and those who purchased FMCG not based on package. Predictor variables were 'picture', 'colour', 'size', 'shape' and 'material'. It was observed that there were significant mean differences for all the predictors on the dependent variable. Even though the log determinants were almost similar, Box's M showed that the assumption of equality of covariance matrices was not met (Geisser and Greenhouse, 1958).But given the sample size to be 240 which is considered to be large for discriminant analysis, this problem was not regarded as that serious. The discriminate function showed a significant relationship between the two groups and all the predictor variables accounting for $64.32 \%$ of between group variability. A closer examination of the structure matrix indicated that only two significant predictors emerged namely 'Colour' (.706) and 'Shape' (-.527) . Other variables namely 'Picture', 'Size' and 'Material' were considered as poor predictors as far as the young consumer segment was considered.. The cross validated classification showed that taken as a whole, $91.8 \%$ of the cases were correctly classified. Thus it was concluded that visual elements ('Colour' and 'Shape') clearly discriminated between those who purchased FMCG based on package and those who purchased FMCG not based on package.

The results of this paper significantly contribute as a new piece of information to package designers while designing their product packages. Designers can now look into which of the visual elements of product packages as detailed in study make significant contribution to product purchases as far as student communities are concerned. The results of this research can be taken as input in designing and developing attractive packages in FMCG industry. This when properly incorporated will bring more revenues through sale of FMCG products by way of their packages.

The study was confined only to a semi urban district of Northern Kerala, Kannur. The sample size drawn was also small. Studies may be extended to a broader region with a bigger sample size. As FMCG is a type of product which is used irrespective of age barriers, the present study can be made more comprehensive by including older people. Such an indepth examination would throw more light in understanding the significant differences if any across several demographic factors. An extended study can also be carried out to understand the difference in purchase pattern if any, across young consumers of urban and rural regions. Many insights can also be raveled by extending the study across diverse products/brands and even on unbranded FMCG. The consumer behavior patterns can be also interpreted with different methods of analysis such as multiple regression, conjoint analysis, SEM analysis, factor analysis, cluster analysis and so on. 


\section{MMCKS References}

Ampuero, O., and Vila, N. (2006), "Consumer perceptions of product packaging”, Journal of Consumer Marketing, Vol. 7, No. 2, pp. 100-112.

Ashby, M. F., \& Johnson, K. (2013), Materials and design: the art and science of material selection in product design, Butterworth-Heinemann.

Bone, P. F., and France, K. R. (2001), "Package graphics and consumer product belief", Journal of Business and Psychology, Vol. 15, No. 3, pp. 467-489.

Clement, J., Kristensen, T., \& Grønhaug, K. (2013), “Understanding consumers' in-store visual perception: The influence of package design features on visual attention",Journal of Retailing and Consumer Services, Vol. 20, No. 2, pp. 234-239.

Fitzgerald, M., and Tsosie, T. (2004), “Cereal Box Design: An Interdisciplinary Graphics Activity", Tech Directions, Vol. 64, No. 1, pp. 22-25.

Geisser, S., and Greenhouse, S. W. (1958), "An extension of box's results on the use of the \$ F \$ distribution in multivariate analysis", The Annals of Mathematical Statistics, Vol. 29, No. 3, pp. 885-891.

Grossman, R. P., and Wisenblit, J. Z. (1999), "What we know about consumers' color choices", Journal of marketing practice: Applied marketing science, Vol. 5, No. 3, pp. 78-88.

Hine, T. (1995), The Total Package, Little Brown: Boston.

Hollywood, L., Wells, L., Armstrong, G., \& Farley, H. (2013). "Thinking outside the carton: attitudes towards milk packaging", British Food Journal, Vol. 115, No. 6, pp. 899912.

Johnson, R. A., and Wichern, D. W. (1992), Applied multivariate statistical analysis, Englewood Cliffs, Prentice hall: NJ.

Lewis, M. (1991), Understanding Brands, Kogan Page: London.

MacInnis, D. J., and Price, L. L. (1987), "The role of imagery in information processing: Review and extensions", Journal of consumer research, pp. 473-491.

Madden, T. J., Hewett, K., and Roth, M. S. (2000), "Managing images in different cultures: a cross-national study of color meanings and preferences", Journal of international marketing, pp.90-107.

Malhotra, N. K. (2004), Marketing Research: An Applied Orientation. Pearson Education Inc: New Jersey.

Meyers-Levy, J., and Peracchio, L. A. (1995), "Understanding the effects of color: How the correspondence between available and required resources affects attitudes", Journal of Consumer Research, pp. 121-138.

Pilditch, J. (1961), The silent salesman: how to develop packaging that sells, Business Publications.

Prendergast, P. G., and Pitt, L. (1996), "Packaging, marketing, logistics and the environment: are there trade-offs?", International Journal of Physical Distribution \& Logistics Management, Vol. 26, No. 6, pp. 60-72.

Raghubir, P., and Greenleaf, E. A. (2006), "Ratios in proportion: what should the shape of the package be?", Journal of Marketing, pp.95-107.

Rettie, R., and Brewer, C. (2000), "The verbal and visual components of package design", Journal of Product \& Brand Management, Vol.9, No.1, pp. 56-70. 
Richardson, P. S., Dick, A. S., and Jain, A. K. (1994), "Extrinsic and intrinsic cue effects on MMCKS perceptions of store brand quality", The Journal of Marketing, pp. 28-36.

Sauvage, F. (1996), Food packaging technology, VHC Publishers: United States

Schoormans, J. P. and Robben, H. S. (1997), "The effect of new package design on product attention, categorization and evaluation", Journal of Economic Psychology, Vol. 18, No. 2, pp. 271-287.

Silayoi, P., and Speece, M. (2004), "Packaging and purchase decisions: an exploratory study on the impact of involvement level and time pressure", British food journal, Vol. 106, No. 8, pp. 607-628.

Silayoi, P. and Speece, M. (2007), "The importance of packaging attributes: a conjoint analysis approach", European Journal of Marketing, Vol. 41, No. 11, pp. 1495-1517.

Sonsino, S. (1990), Packaging Design: Graphics, Materials, Technology, Thames and Hudson: London.

Underwood, R. L. (2003), "The communicative power of product packaging: creating brand identity via lived and mediated experience", Journal of Marketing Theory and Practice, pp. 62-76.

Underwood, R. L., Klein, N. M., and Burke, R. R. (2001), "Packaging communication: attentional effects of product imagery", Journal of Product \& Brand Management, Vol. 10, No.7, pp. 403-422.

Vazquez, D., Bruce, M., and Studd, R. (2003), "A case study exploring the packaging design management process within a UK food retailer", British Food Journal, Vol. 105, No.9, pp. 602-617. 